\title{
Sibling Jealousy in Early Childhood: Longitudinal Links to Sibling Relationship Quality
}

\author{
Amy M. Kolak ${ }^{a, *}$ and Brenda L. Volling ${ }^{\mathrm{b}}$ \\ a Department of Psychology, College of Charleston, Charleston, SC, USA \\ ${ }^{\mathrm{b}}$ Department of Psychology, University of Michigan, Ann Arbor, MI, USA
}

The current investigation examined the long-term prediction of sibling jealousy assessed in a laboratory-based paradigm on sibling relationship quality $21 / 2$ years later. This multi-method longitudinal study included mothers, fathers, and two children from 35 families. Younger siblings were 16 months and older siblings were, on average, 4 years at Time 1 . Positive longitudinal associations were found between older siblings' jealousy reactions when interacting with the father at Time 1 and sibling conflict at Time 2. These associations continued to exist even when older siblings' behaviour during the mother sessions was considered. Children's inability to regulate their jealous reactions may be indicative of lower levels of emotion regulation skills, which may, in turn, translate to poorer sibling interactions years later. Copyright (C) 2010 John Wiley \& Sons, Ltd.

Key words: siblings; jealousy; conflict; fathers

During early childhood, children are faced with a number of developmental tasks, including the regulation of emotions and behaviour, and the sibling relationship is one context in which children attempt to master these goals (Bedford \& Volling, 2004). There is considerable variability in the nature of siblings' relationships (Dunn \& Munn, 1986). Even though siblings behave positively toward each other, conflict between siblings is normative and for many parents of two or more children, sibling conflict is a major concern. Parents are especially concerned with managing sibling conflict (Perozynski \& Kramer, 1999), which may be one reason why this topic draws a great deal of attention in the popular press and why a number of parenting guides are directed at handling sibling rivalry and conflict (e.g. Faber \& Mazlish, 1998; Goldenthal, 1997; Samalin \& Whitney, 1997).

Although laypeople and researchers alike do not make distinctions between rivalry, conflict, and jealousy in the sibling relationship, these are distinct, though

\footnotetext{
*Correspondence to: Amy M. Kolak, Department of Psychology, College of Charleston, 57 Coming Street, Charleston, SC 29401, USA. E-mail: kolaka@cofc.edu
} 
intertwined, features of sibling relationships (Neubauer, 1983). According to several theoretical perspectives, jealousy occurs within the context of a social triangle that involves the jealous person, the beloved, and the rival. In the case of sibling jealousy, Volling and her colleagues (Miller, Volling, \& McElwain, 2000; Volling, Kennedy, \& Jackey, in press; Volling, McElwain, \& Miller, 2002) found that the social triangle includes both siblings and another person (usually the mother or father). Jealousy is elicited when one child (i.e. the jealous person) experiences the loss of the parent's (i.e. the beloved) attention and/or affection to a sibling (i.e. the rival). Sibling conflict, in contrast, refers to the unique interpersonal dyadic dynamics of sibling interactions, which may be motivated by, but are not synonymous with sibling jealousy. The main goal of the current report was to examine whether sibling jealousy in early childhood predicted higher levels of conflict in the sibling relationship during the preschool and early elementary school years.

\section{Sibling Jealousy}

Despite the attention that sibling jealousy has garnered in the popular press, jealousy between siblings during early childhood has received scant attention from developmental and family researchers. Volling et al. (in press) provide a conceptual framework for understanding and assessing sibling jealousy which is based, in part, on the theoretical writings of White and Mullen (1989), as well as a family system's perspective (Cox \& Paley, 2003). In this transactional model of jealousy, Volling et al. (in press) argue that jealousy is both an intrapersonal and interpersonal phenomenon. As noted earlier, the social triangle consisting of the jealous child, the rival sibling and the beloved parent constitute the interpersonal system and the relationships between the three individuals can bidirectionally influence each other as well as the individual's affect and behaviour. Jealousy is viewed by Volling et al. (in press) as a complex social emotion that consists of affective (A), behavioural (B) and cognitive (C), components which form an individual's jealousy complex. The jealousy complex can differ across individuals depending on the cognitive appraisal a person makes when they believe their primary relationship with their beloved is threatened by the rival. For instance, a child who interprets the parent's attention and affection directed at their sibling as betrayal may feel angry and react with aggression.

In an earlier study, Miller et al. (2000) designed a laboratory-based paradigm that consisted of 3-min triadic sessions involving a toddler, an older sibling, and a parent in order to elicit jealousy. The parent was asked to first focus his or her attention on one sibling (target child) and play with that child for $3 \mathrm{~min}$, while the other sibling was asked to play with additional toys in the room (challenged child). The parent then switched his or her attention and focused on the other sibling for $3 \mathrm{~min}$. The parent was asked to play with both children during the final 3-min session to alleviate any distress caused by the previous two sessions. The jealousy paradigm reliably evoked more negative and less positive emotions from younger and older siblings when they were challenged (non-target) than when they were the focus of their parents' attention (Miller et al., 2000; Volling et al., 2002, in press). Toddler siblings exhibited more generalized distress (e.g. crying, whining, and fussing) whereas older siblings displayed more sadness and anger when the parent's attention was focused on the other sibling. Both siblings often attempted to physically intrude upon the parent's interaction with the sibling and in some cases, even hit or pushed the parent or sibling. In some cases, 
challenged siblings used distraction (e.g. playing with toys) to regulate their jealousy. Preschool-aged siblings, as expected, demonstrated better self-regulation during the challenge context than their younger toddler siblings though there was still considerable variability in their self-regulatory skills (Kopp, 1989; Sroufe, 1996). The current study focuses on the behavioural and affective components of sibling jealousy assessed in the jealousy paradigm in toddlerhood and their prediction of subsequent sibling relationship quality.

Families in the Volling et al. (2002) were recontacted approximately $21 / 2$ years later when the younger sibling was 4 years old. Thus, the primary aim of this study was to examine the longitudinal associations between sibling jealousy observed in the triadic laboratory paradigm when the younger sibling was 16 months old and sibling interactions when the younger sibling was 4 years old. We hypothesized that children who exhibited more jealous affect and behavioural dysregulation during the triadic laboratory paradigm in toddlerhood would engage in more sibling conflict and display more negative affect toward their siblings $21 / 2$ years later.

\section{Siblings' Jealousy Reactions with Mothers and Fathers}

An additional strength of the current research is the inclusion of triadic sessions involving children with their fathers. Because Volling et al. (2002) reported that children's jealousy reactions with mothers were not associated with their jealousy reactions in triadic sessions with their fathers, considering children's behaviour across mother and father sessions may further our understanding of the role that family dynamics play in the developing sibling relationship.

Two models were tested to examine children's behaviour across the mother and father sessions on sibling relationship quality. The first, a direct effects model, considered the simultaneous contributions of children's affect and behaviour during both parent sessions on the quality of children's sibling relationships. The second, an interactive model, examined the interaction between the child's behaviour during the mother session and the child's behaviour during the father session on sibling relationship quality. Children who are better able to regulate their emotions (i.e. jealousy) in at least one of the triadic sessions (mother or father) may be better equipped to form more positive relationships with their siblings than children who are either highly dysregulated or exhibit more jealous affect across both sessions. Specifically, we hypothesized that children who were more dysregulated or exhibited strong jealousy reactions during the sessions with their mothers and fathers would be at an increased risk for engaging in poorer sibling interactions years later.

\section{METHOD}

\section{Participants}

Participants included mothers, fathers, and two children in a short-term longitudinal study of children's family relationships conducted when the younger sibling was 16 months old $(n=62)$. Families were initially recruited from birth announcements, local daycare centers, and referrals from participating families. These families were later contacted and asked to participate in a second study on children's social relationships with siblings and friends when the younger sibling was 4 years of age. Of the 62 families who participated initially at 
16 months (Time 1), 37 families agreed to participate in the longitudinal followup at 4 years (Time 2). Two families were excluded from the current investigation due to missing data at Time 1 . The 35 families available for analysis did not differ on demographic characteristics (e.g. age, educational level, income, years married, number of children, and age of older child) or Time 1 variables (e.g. children's jealousy reactions) from the 25 families who could not be reached or declined to participate.

Families were predominantly European American and included one Native American family. At Time 1, parents had been married for an average of 11.5 years (S.D. $=3$ years). On average, fathers were 39.7 years old and had completed 17.2 years of education, whereas mothers were, on average, 36.8 years old and had completed 16.3 years of education. The mean family income was $\$ 85808$ $($ S.D. $=\$ 39645)$. Younger siblings were 16 months old at Time 1 and older siblings were, on average, 4.3 years old (S.D. $=1.2$ years). When the younger siblings were 4 (Time 2 ), the mean age of the older siblings was 7.2 years (S.D. $=1.2$ years). Most of the younger siblings $(n=23)$ were second-born; the remaining 12 were third- through fifth-born. This sample included 8 boy/boy dyads (older/ younger), 11 girl/girl dyads, 6 boy/girl dyads, and 10 girl/boy dyads.

\section{Design and Procedures}

During the initial study, families participated in laboratory visits when younger siblings were 12, 13, and 16 months old (see Miller et al., 2000 for detailed description of study design and procedures). Data for the current investigation are drawn from the two, 9-min triadic laboratory sessions involving parents and siblings at the 16-month visit (Time 1) which was approximately $90 \mathrm{~min}$ long. The follow-up study consisted of two laboratory visits when the younger siblings were 4 and included assessments of sibling and friend interactions (Time 2). The 4-year sibling visit was approximately $60 \mathrm{~min}$ (see McElwain \& Volling, 2005 for a complete description of visit procedures) and consisted of several interaction tasks including a 20-min freeplay interaction between siblings. Mothers and fathers also completed questionnaires about sibling relationship quality at Time 2. Laboratory visits at Time 1 and Time 2 were conducted at times that were convenient for the participating families and thus, time of day for these sessions varied across families.

\section{Sibling Jealousy at Time 1}

At the 16-month visit, siblings were videotaped in a 9-min triadic interaction paradigm (once with mother and once with father; sessions were counterbalanced) designed to elicit sibling jealousy (see Miller et al., 2000 for detailed information about this paradigm, coding, and reliability). The parent was given an attractive toy (either a Lego ${ }^{\mathrm{TM}}$ playset or a talking Sesame Street phone) to use throughout the interaction. During the first 3-min session of the interaction, the parent was instructed to play with either the toddler or the older sibling (the target child; determined by counterbalancing) while persuading the other child (the challenged child) to play with other toys in the room. At the end of $3 \mathrm{~min}$, the parent was asked to turn his or her attention to the other child and play with this child for the second 3-min session. The other sibling was now encouraged by the parent to play with other toys in the room (i.e. they were now the non-target, challenged child) while the parent engaged in dyadic play with the target child. For the final $3 \mathrm{~min}$, the parent was asked to play with both children to 
alleviate any distress that may have been elicited during the previous two sessions. This paradigm reliably elicited negative emotional reactions for both 16-month olds and their older siblings when comparing affect across the challenged and target sessions (Miller et al., 2000).

Toddlers' and older siblings' emotions and behaviours were coded from the videotaped challenge sessions with mother and father by independent coders. Coders were trained until interobserver agreement was $80 \%$ or higher. Reliabilities were calculated for approximately $20 \%$ of the sample ( $\kappa$ s are provided in parentheses). Toddlers' and older siblings' emotions (distress for toddlers and sadness and anger for older siblings) were coded using a system adapted from Cole, Barrett, and Zahn-Waxler (1992). Emotional displays were coded globally on a 7-point scale, ranging from $0=$ no display of emotion during session to $6=$ frequent and full displays of emotion across session. Distress $(\kappa=0.72)$ assessed toddlers' displays of fussiness, whining, and crying that were in response to the parent's involved play with the older sibling. Sadness $(\kappa=0.82)$ captured older siblings' behavioural cues such as a turned-down facial expression, whiny voice, and slackening of muscular tone in face or body. Anger $(\kappa=0.77)$ assessed children's hostility and was captured by a hostile, annoyed, or harsh tone of voice.

Behavioural coping strategies (distraction and play involvement for both siblings and hostility for older children) were coded in 15-s intervals from the videotaped challenge sessions (see Miller et al., 2000). Distraction $(\kappa=0.82)$ assessed toddlers' and older siblings' distracting behaviour during the session (e.g. whether or not the child placed himself or herself between the parent and sibling during the activity). Play involvement ( $\kappa=0.87$ for older sibling and $\kappa=0.84$ for toddler) was coded on a 3-point scale ranging from $1=$ uninvolved in play by self to $3=$ fully involved with a toy or an activity by self. Hostility $(\kappa=0.60)$ was coded as present or absent during each 15-s interval and captured negativity (e.g. hitting, pushing) toward parent, negativity toward sibling, and rough play (e.g. banging toy in an aggressive or inappropriate manner). Mean scores were created for each behaviour by summing across the 15-s intervals and then dividing by the number of intervals.

Based on intercorrelations among emotional expressions and behavioural coping strategies (Volling et al., 2002), two composites were created for each child. One composite reflected Jealous Affect and was created by standardizing and summing sadness and anger for older children and using the distress score alone for toddlers. The second composite reflected Behavioural Dysregulation and was created by standardizing and summing distraction and hostility and subtracting play involvement for older children, and standardizing and subtracting play involvement from distraction for toddlers.

\section{Individual and Dyadic Behaviour During Sibling Freeplay at Time 2}

At the 4-year assessment, the siblings were left alone to play for $20 \mathrm{~min}$ with a variety of age-appropriate toys (e.g. building blocks, basketball hoop and ball, kitchen set, workbench, and castle and figures). These sessions were videotaped and coded for individual behaviour and dyadic interaction in 15-s intervals by different teams of coders (McElwain \& Volling, 2005).

\section{Individual behaviour}

Younger and older siblings' sadness, anxiety, and anger were individually rated across the videotaped freeplay interaction. Coders were trained until interobserver agreement was $80 \%$ or higher and reliabilities were calculated for 
approximately $20 \%$ of the sample ( $\kappa$ s are in parentheses). A 3-point scale was used to capture the combined frequency, intensity, and duration of each emotion every $15 \mathrm{~s}$. The scale ranged from $0=$ no instance of emotion to $2=$ multiple instances and/or an intense instance of emotion. Sadness $(\kappa=0.78)$ assessed children's displays of glumness, tearfulness, and wistfulness and was captured by children's behavioural cues such as talking in a voice that was low in tone and/or volume and having a facial expression where the corners of the mouth were turned down and/or the eyebrows were furrowed. Anxiety $(\kappa=0.70)$ assessed children's nervousness and fearfulness during the interaction and this emotion was captured by fidgety behaviour and gaze avoidance. Anger $(\kappa=0.52)$ assessed children's hostility and was captured by a harsh or insistent tone of voice and facial cues that included a jutting jaw, a square-shaped mouth, lips pressed together, or eyes in a hard stare. Mean ratings for each emotion were calculated by averaging across the 15-s intervals. Because the $\kappa$ for anger was low and because children's anger was not consistently related to sadness or anxiety for either sibling, it was dropped from further consideration. However, sadness and anxiety were significantly correlated for younger $(r=0.34, p=0.05)$ and older $(r=0.37, p<0.05)$ siblings. We averaged across sadness and anxiety for each sibling to create a variable tapping negative affect during sibling interaction.

\section{Dyadic interaction}

The quality of dyadic sibling interaction was captured through variables that were coded during 15-s intervals. For the purposes of the current study, we examined conflict intensity $(\kappa=0.69)$ which assessed the degree to which children were involved in mutual opposition and was rated on a 3-point scale, ranging from 0 (no conflict) to 2 (extended and/or intense conflict). Mean ratings for conflict were calculated by averaging across the 15-s intervals.

\section{Parental Reports of Sibling Behaviour at Time 2}

To assess children's behaviour toward their siblings, mothers and fathers completed a 32-item modified version of the Sibling Inventory of Behaviour (Hetherington \& Clingempeel, 1992; Schaefer \& Edgerton, 1981). Each item was rated from $1=$ never to 5 =always and comprised six sibling relationship scales: involvement, empathy, teaching, rivalry, avoidance, and aggression. We were only interested in examining the 12-item sibling conflict scale which is comprised of the rivalry and aggression subscales (for older sibling, $\alpha=0.93$ and 0.91 for mothers and fathers, respectively; for younger sibling, $\alpha=0.89$ and 0.89 for mothers and fathers, respectively). Example items included, 'is very competitive with sibling', 'hurts sibling's feelings', and 'gets angry with sibling'. Strong concordance between mothers' and fathers' ratings of sibling conflict for the older siblings $(r=0.64, p<0.001)$ and younger siblings $(r=0.64, p<0.001)$ led us to average mothers' and fathers' ratings for each child to create more robust composites of sibling conflict. Descriptive statistics for the sibling relationship quality variables, along with the correlations among these variables, can be found in Table 1 .

\section{RESULTS}

Correlations and one-way analysis of variances (ANOVAS) were conducted to examine whether the indicators of sibling relationship quality at Time 2 differed 
Table 1. Descriptive statistics for and correlations among sibling relationship quality variables at Time 2

\begin{tabular}{|c|c|c|c|c|c|c|}
\hline & \multirow[t]{2}{*}{$M$} & \multirow[t]{2}{*}{ S.D. } & \multicolumn{2}{|c|}{ Parental reports } & \multicolumn{2}{|c|}{ Sibling freeplay } \\
\hline & & & $\begin{array}{l}\text { Younger } \\
\text { sibling } \\
\text { conflict }\end{array}$ & $\begin{array}{l}\text { Older } \\
\text { sibling } \\
\text { conflict }\end{array}$ & $\begin{array}{l}\text { Younger } \\
\text { sibling } \\
\text { negative } \\
\text { affect }\end{array}$ & $\begin{array}{l}\text { Older } \\
\text { sibling } \\
\text { negative } \\
\text { affect }\end{array}$ \\
\hline \multicolumn{7}{|l|}{ Parental reports } \\
\hline Younger sibling conflict & 33.32 & 6.62 & & & & \\
\hline $\begin{array}{l}\text { Older sibling conflict } \\
\text { Sibling freeplay }\end{array}$ & 34.99 & 7.39 & $0.64^{* * *}$ & & & \\
\hline $\begin{array}{l}\text { Younger sibling } \\
\text { negative affect }\end{array}$ & 0.00 & 1.64 & -0.14 & -0.20 & & \\
\hline $\begin{array}{l}\text { Older sibling negative } \\
\text { affect }\end{array}$ & 0.00 & 1.65 & 0.08 & 0.22 & $0.42 *$ & \\
\hline Conflict intensity & 0.02 & 0.02 & 0.15 & 0.18 & 0.03 & 0.05 \\
\hline
\end{tabular}

The variables, sadness and anxiety, were standardized and summed to create the negative affect scores. ${ }^{*} p<0.05,{ }^{* *} p<0.01,{ }^{* * *} p<0.001$.

as a function of the older siblings' age, child gender, or gender composition of the sibling dyad. Older siblings' age was not significantly correlated with parental reports of sibling conflict or observed sibling interactions. One-way ANOVAS examining younger siblings' gender and the gender constellation of the sibling dyad were non-significant; however, differences were found for older siblings' gender. Parental reports of older siblings' conflict differed, $F(1,32)=5.39, p<0.05$, such that parents of sons reported more sibling conflict $(M=38.50)$ than parents of daughters $(M=32.81)$. Older siblings' gender was controlled in all subsequent analyses (including correlations) examining older siblings' individual behaviour (i.e. parental reports of conflict and negative affect during sibling freeplay) and sibling conflict. ${ }^{1}$

\section{Associations between Jealous Behaviour and Sibling Interaction}

To address the primary aim of the study, we examined the correlations between younger and older siblings' jealousy reactions during the mother and father triadic sessions at Time 1 and sibling interactions at Time 2 (Table 2). Older siblings' jealous affect and behavioural dysregulation with their mothers at Time 1 was not significantly correlated to parental reports of the older siblings' conflict or observed sibling conflict at Time 2. Significant associations emerged between older siblings' behaviour during the triadic father sessions at Time 1 and sibling interactions at Time 2. Older siblings' jealous affect and behavioural dysregulation during the father sessions at Time 1 were significantly correlated to parental reports of conflict at Time 2. Older siblings who exhibited more behavioural dysregulation during the father sessions at Time 1 also exhibited more negative affect and higher levels of conflict intensity during sibling interactions at Time 2.

Younger siblings who exhibited more jealous affect during the mother sessions at Time 1 engaged in more conflict, as reported by their parents, at Time 2 (Table 2). Jealous affect during the mother session was not associated with observed sibling interactions. Neither younger siblings' behavioural 
Table 2. Correlations between jealousy variables at Time 1 and sibling relationship quality at Time 2

\begin{tabular}{|c|c|c|c|}
\hline & \multirow{2}{*}{$\frac{\text { Parental reports }}{\text { Sibling conflict }}$} & \multicolumn{2}{|c|}{ Sibling freeplay } \\
\hline & & Negative affect & Conflict intensity \\
\hline \multicolumn{4}{|l|}{ Father sessions } \\
\hline \multicolumn{4}{|l|}{ Younger sibling } \\
\hline Jealous affect & -0.20 & -0.14 & 0.26 \\
\hline Behavioral dysregulation & -0.14 & -0.11 & 0.18 \\
\hline \multicolumn{4}{|l|}{ Older sibling } \\
\hline Jealous affect & $0.55^{* *}$ & $0.33^{\dagger}$ & 0.19 \\
\hline Behavioral dysregulation & $0.52^{* *}$ & $0.41^{*}$ & $0.39^{*}$ \\
\hline \multicolumn{4}{|l|}{ Mother sessions } \\
\hline \multicolumn{4}{|l|}{ Younger sibling } \\
\hline Jealous affect & $0.37^{*}$ & -0.29 & 0.04 \\
\hline Behavioral dysregulation & 0.16 & 0.12 & -0.17 \\
\hline \multicolumn{4}{|l|}{ Older sibling } \\
\hline Jealous affect & 0.20 & 0.18 & 0.10 \\
\hline Behavioral dysregulation & 0.17 & 0.23 & 0.25 \\
\hline
\end{tabular}

Older sibling gender used as a covariate in all correlations for older siblings and in younger sibling correlations that include the conflict intensity variable. ${ }^{\dagger} p=0.06,{ }^{*} p<0.05,{ }^{*} * p<0.01$.

dysregulation during the mother sessions nor their jealous affect and behavioural dysregulation during father sessions at Time 1 were significantly correlated with parental reports of sibling conflict or observed sibling interactions at Time 2.

\section{Regression Models}

To address the second aim, we conducted a series of regression models to examine simultaneously the direct effects of children's behaviour across the sessions with mother and father at Time 1 on sibling relationship quality at Time 2. We tested five regression models, one to follow up each of the significant correlations, which resulted in four models for older siblings and one model for younger siblings. The older sibling models included older siblings' gender, the older siblings' behaviour during the mother session, and the older siblings' behaviour during the father session. The younger sibling model included the younger siblings' behaviour during the mother session and the younger siblings' behaviour during the father session. Though we would have preferred to include children's jealous affect and behavioural dysregulation together in the models; our statistical power was limited by our small sample size so we examined each in separate models. As shown in Table 3, older siblings' behaviour during the father session continued to be a significant predictor of parent-reported and observed sibling interactions even when the child's behaviour during the mother session was included in the model. The corresponding effect sizes for older siblings' behaviour with fathers ranged from 0.33 to 0.47 indicating moderate effects (Cohen, 1988). For the model examining parental reports of the younger siblings' conflict, jealous affect with mother continues to be a significant predictor even when the child's jealous affect during the father session is included. ${ }^{2}$ The corresponding effect size for younger siblings' jealous affect with mother was 0.38 indicating a moderate effect (Cohen, 1988). 
Table 3. Predicting sibling interactions at Time 2 with child behavior during mother and father sessions at Time 1

\begin{tabular}{|c|c|c|}
\hline Models and predictors & $\beta$ & S.E. $B$ \\
\hline \multicolumn{3}{|l|}{ Older sibling models } \\
\hline Older sibling gender & $-0.29^{*}$ & 2.17 \\
\hline Jealous affect with mother & 0.04 & 0.60 \\
\hline Jealous affect with father & $0.51^{* *}$ & 0.62 \\
\hline Total $R^{2}$ & 0.41 & \\
\hline$F(3,30)$ & $6.86^{* *}$ & \\
\hline \multicolumn{3}{|l|}{ Sibling conflict } \\
\hline Older sibling gender & -0.24 & 2.28 \\
\hline Behavioral dysregulation with mother & 0.04 & 0.45 \\
\hline Behavioral dysregulation with father & $0.48^{* *}$ & 0.45 \\
\hline Total $R^{2}$ & 0.37 & \\
\hline$F(3,30)$ & $5.86^{* *}$ & \\
\hline \multicolumn{3}{|l|}{ Negative affect } \\
\hline Older sibling gender & 0.19 & 0.57 \\
\hline Behavioral dysregulation with mother & 0.14 & 0.11 \\
\hline Behavioral dysregulation with father & $0.39^{*}$ & 0.11 \\
\hline Total $R^{2}$ & 0.19 & \\
\hline$F(3,30)$ & $2.39^{\dagger}$ & \\
\hline \multicolumn{3}{|l|}{ Conflict intensity } \\
\hline Older sibling gender & -0.21 & 0.01 \\
\hline Behavioral dysregulation with mother & 0.16 & 0.00 \\
\hline Behavioral dysregulation with father & $0.34^{\dagger}$ & 0.00 \\
\hline Total $R^{2}$ & 0.26 & \\
\hline$F(3,30)$ & $3.55^{*}$ & \\
\hline \multicolumn{3}{|l|}{ Younger sibling model } \\
\hline \multicolumn{3}{|l|}{ Sibling conflict } \\
\hline Jealous affect with mother & $0.35^{*}$ & 1.08 \\
\hline Jealous affect with father & -0.29 & 1.16 \\
\hline Total $R^{2}$ & 0.18 & \\
\hline$F(2,30)$ & $3.27^{*}$ & \\
\hline
\end{tabular}

${ }^{\dagger} p<0.10,{ }^{*} p<0.05,{ }^{* *} p<0.01$.

\section{Interactive Regression Models}

To test for interactive effects, a second step was added to each of the above five models that included the interaction term between the child's behaviour during the mother session and the child's behaviour during the father session. These analyses were conducted following the guidelines of Aiken and West (1991) and significant interactions were graphed using high and low values $(+1$ and -1 S.D.) of each of the variables. Simple slopes analyses were conducted to test whether the plotted regression lines were significantly different from zero. A slope significantly different from zero indicates that for a particular level of the moderator there is a significant relationship between the independent and dependent variables (Aiken \& West, 1991).

Five models were tested; however, only one significant interaction emerged. A significant interaction was found for older siblings' behavioural dysregulation during the father session and older siblings' behavioural dysregulation during the mother session at Time 1 predicting negative affect during the sibling freeplay at Time 2, $\beta=0.49, \mathrm{SE}=0.05, t=2.65, p<0.05$, overall $R^{2}=0.35, F(4,29)=3.91$, $p<0.05$. The inclusion of this interaction in the model accounted for additional 


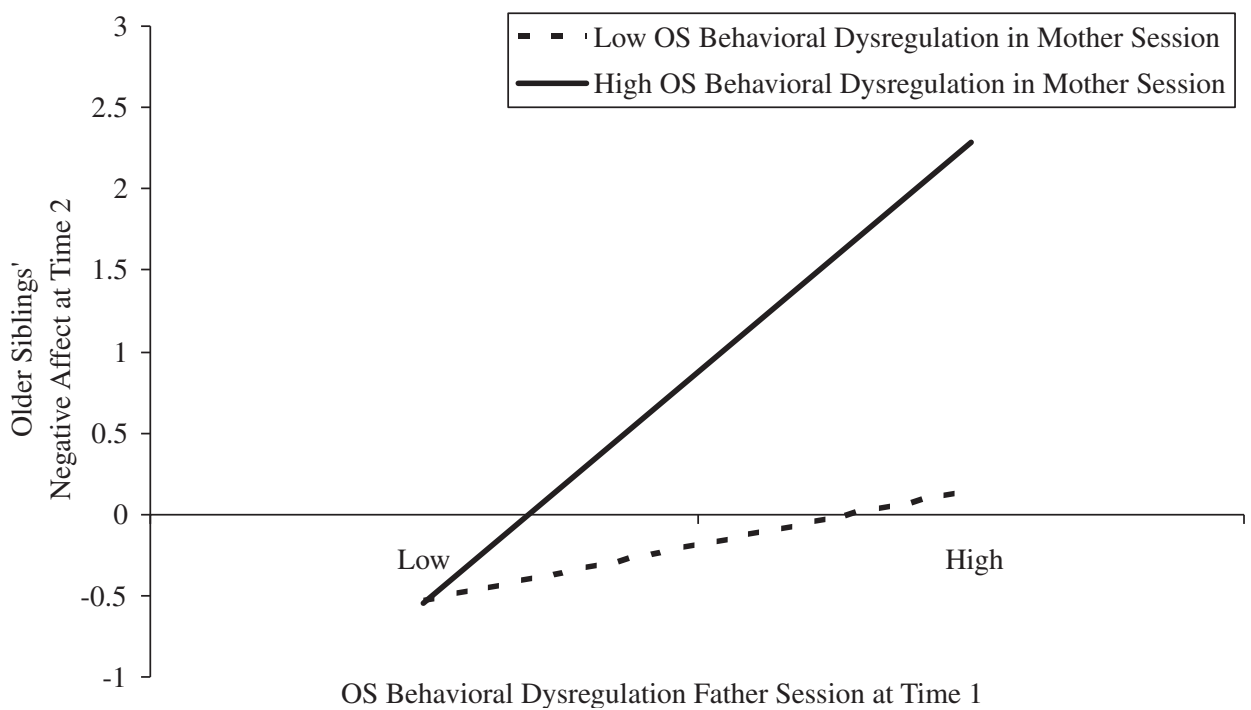

Figure 1. The interaction between older siblings' behavioural dysregulation during mother session and behavioural dysregulation during the father session at Time 1 on negative affect at Time 2 .

variance in older siblings' negative affect, $\Delta R^{2}=0.16, F$ Change $=7.00, p<0.05$, above and beyond the model examining only the direct effects of older siblings' behavioural dysregulation during each parent session. The corresponding effect size for the interaction was 0.42 indicating a moderate effect (Cohen, 1988). As exemplified in Figure 1, when older siblings' behavioural dysregulation during the mother session at Time 1 was high, there was a significant association between behavioural dysregulation during the father session at Time 1 and negative affect during the sibling freeplay at Time $2(b=0.56, p=0.001)$. There was no association, however, between older siblings' behavioural dysregulation during the father session at Time 1 and negative affect at Time 2 when behavioural dysregulation during the mother session at Time 1 was low $(b=-0.13$, $p=0.47$ ). In other words, it was the combination of older siblings' behavioural dysregulation with mother and father that predicted older siblings' negative affect over 2 years later.

\section{DISCUSSION}

Children's ability to regulate emotions during social interactions is a critical component for successful interpersonal interactions (Blair, Denham, Kochanoff, \& Whipple, 2004). Yet, little is known about children's reactions to jealousyprovoking situations in early childhood and the quality of the relationships that ensue between siblings. Findings from the current investigation supported our hypothesis that jealous affect and behavioural dysregulation would be related to more troubled sibling interactions 2 years later. This is clearly consistent with prior research demonstration that has demonstrated stability in negative sibling interactions (Dunn, Slomkowski, \& Beardsall, 1994). There were two striking patterns to our findings. First, we found more longitudinal associations for older siblings than younger siblings when examining jealous reactions and their 
prediction of sibling conflict. Second, it was the older siblings' behaviour during the father sessions at Time 1, rather than during the mother sessions, that predicted the quality of the sibling relationships at Time 2 .

\section{Older Siblings' Behaviour More Predictive than Younger Siblings' Behaviour}

Because older siblings are often the leaders, managers, and teachers of their younger siblings during preschool and middle-childhood (Brody, Stoneman, MacKinnon, \& MacKinnon, 1985; Buhrmester \& Furman, 1990; Vandell, Minnett, \& Santrock, 1987), they are the more dominant partner in the sibling relationship and exert more influence on sibling relationships throughout early childhood (Dunn, 1985; Stoneman, Brody, \& MacKinnon, 1984). Older siblings' behaviour toward their younger siblings was more stable from preschool through middle childhood than younger siblings' behaviour toward their older siblings (Dunn et al., 1994). This stability, along with the more dominant role of older siblings, may explain why older siblings' jealousy reactions, rather than younger siblings' jealousy, were stronger predictors of the sibling relationship a few years later.

\section{Older Siblings' Behaviour During Father Sessions}

Not only did older siblings' reactions during the jealousy paradigm have more predictive utility for sibling interactions than the younger siblings' reactions, but it was specifically the older siblings' jealous reactions with fathers that were more predictive of sibling interactions $21 / 2$ years later. This is consistent with our earlier finding that older siblings' jealous reactions during the father sessions were related to parents' reports of sibling conflict (Volling et al., 2002). Further, research demonstrates that some fathers become more involved in the care of an older child after the birth of a sibling because mothers are preoccupied with caring for the newborn (Kreppner, 1988; Legg, Sherick, \& Wadland, 1974). Thus, the father-older sibling relationship may strengthen as the child matures and be particularly close. Dunn (1985) found that older siblings were often distressed when their fathers interacted with their infant siblings, underscoring the idea that older siblings might view the relationship with their fathers as 'special'. As the infant sibling becomes a mobile toddler and demands more attention, an older sibling may be keenly aware of the infant's intrusions on his or her 'special' relationship with the father. The special closesness in the father-child relationship may explain why in the current study, older siblings' jealous reactions during father sessions, rather than their jealousy during mother sessions, predicted later sibling behaviour.

With the exception of the association between toddlers' jealous affect during mother-older sibling interactions and later sibling conflict, children's behaviour during the mother sessions did not have the same explanatory prediction of sibling relationship quality as children's behaviour during father sessions. However, it is interesting that when toddlers' affect was related to later sibling interaction, it was the affect expressed in relation to the mother and older sibling. Given the age of toddlers at Time 1 (16 months), attachment to a primary caregiver, which in most instances is the mother, is a significant indicator of early emotional development (Sroufe, 1996) and may explain why toddler affect with mothers was more predictive than affect with fathers. 


\section{Children's Behaviour During Mother and Father Sessions}

To address the second aim of the study, we examined whether the positive associations between children's jealous reactions and later sibling conflict would continue to exist once the child's behaviour with the other parent was included in the model. We found that older siblings' jealous reactions in response to their fathers' interactions with their younger siblings independently predicted sibling relationship functioning above the effect of the child's jealousy with mother. Children learn to regulate their emotions within the context of the sibling relationship (Bedford \& Volling, 2004; Brody, Stoneman, Smith, \& Gibson, 1999; Kennedy \& Kramer, 2008). For example, Brody et al.(1999) found, in a sample of 9- to 12-year-old African-American youth, that higher self-regulation was related to more harmony and less conflict in the sibling relationship. Similarly, an intervention that promoted emotion regulation skills in sibling dyads between 4 and 8 years of age led to more positive sibling relationships (Kennedy \& Kramer, 2008). Thus, in the current study, older siblings' inability to regulate their jealousy within the context of triadic interactions may be illustrative of less-developed emotion regulation skills that persist over time and predict subsequent sibling conflict.

We did not find overwhelming support for our third and final hypothesis that children's behaviour across the mother and father sessions would interact to predict sibling relationship quality. Only one interaction emerged: older siblings' behavioural dysregulation during the father session and their behavioural dysregulation during the mother session interacted to predict negative affect during sibling interaction at 4 years. Older siblings who were highly dysregulated during the sessions with both their mothers and fathers were at an increased risk for expressing more negative affect during observed sibling interactions. Again, it appears that children's inability to regulate their jealous anger may be indicative of poor emotion regulation skills, which may, in turn, be detrimental to sibling relationships (Bedford \& Volling, 2004; Stoneman et al., 1984). In contrast, older siblings who were less behaviourally dysregulated (i.e. better able to regulate their jealous reactions) during at least one (or both) of the triadic play sessions with their parents appeared to have the requisite emotion regulation skills for engaging positively with their siblings.

\section{LIMITATIONS AND FUTURE DIRECTIONS}

Even though the current study provides support for the predictive validity of sibling jealousy elicited in a laboratory-based observational paradigm on children's sibling interactions several years later, this investigation is not without its limitations. First, the sample was composed of primarily white, middle-class families raising young children, thus, limiting our ability to generalize these findings to other populations. Future research in this area would benefit from samples that include families from different cultural and economic backgrounds in order to fully appreciate individual differences in children's jealousy reactions.

Second, the small sample size prevented us from considering the role that younger and older sibling's gender may play in the developing sibling relationship. We controlled for older sibling gender in the current investigation; however, a larger sample would have enabled us to examine whether the pattern of associations between jealousy and sibling interactions vary as a function of child gender. Research with older children found that opposite-sex sibling pairs 
were treated more unequally (McHale, Updegraff, Jackson-Newsom, \& Crouter, 2000). This unequal treatment could lead to more sibling jealousy and poorer sibling relationships. Future research should consider links between siblings' gender, sibling jealousy, and differential treatment with larger samples. Finally, the findings from this investigation draw links between sibling jealousy and sibling relationship quality during early childhood. Additional longitudinal investigations are necessary to document the developmental progression of sibling jealousy and its influence on sibling behaviour across other periods of childhood and even into adulthood.

\section{Notes}

1. Similar analyses had been performed on the 16-month jealousy variables and are reported in Miller et al. (2000). There were no significant gender or age effects.

2. Examing children's temperament as a correlate of sibling relationship quality was not an aim of this study; however, given the significant role that temperamental anger played in an earlier study of children's jealous reactions (Volling et al., 2002), we wanted to rule out temperament as a possible alternative explanation for the longitudinal associations between jealous reactions and sibling relationship quality. Temperamental anger was significantly related to parents' reports of sibling conflict; therefore, for these three regression models predicting sibling conflict we included temperamental anger as a covariate. Findings from these analyses were consistent with those reported here such that older sibling's behavior with father continued to predict parents' reports of sibling conflict and younger sibling's jealous affect with mother continued to predict parents' reports of sibling conflict when temperamental anger was included in the models.

\section{REFERENCES}

Aiken, L. S., \& West, S. G. (1991). Multiple regression: Testing and interpreting interactions. Newbury Park, CA: Sage.

Bedford, V. H., \& Volling, B. L. (2004). A dynamic ecological systems perspective on emotion regulation development within the sibling relationship context. In F. R. Lang, \& K. L. Fingerman (Eds.), Growing together: Personal relationships across the lifespan (pp. 76-102). New York, NY: Cambridge University Press.

Blair, K. A., Denham, S. A., Kochanoff, A., \& Whipple, B. (2004). Playing it cool: Temperament, emotion regulation, and social behavior in preschoolers. Journal of School Psychology, 42, 419-443. DOI: 10.1016/j.jsp.2004.10.002.

Brody, G. H., Stoneman, Z., MacKinnon, C. E., \& MacKinnon, R. (1985). Role relationships and behavior between preschool-aged and school-aged sibling pairs. Developmental Psychology, 21, 124-129. DOI: 10.1037/0012-1649.21.1.124.

Brody, G. H., Stoneman, Z., Smith, T., \& Gibson, N. M. (1999). Sibling relationships in rural African American families. Journal of Marriage and the Family, 61, 1046-1057. DOI: $10.2307 / 354023$.

Buhrmester, D., \& Furman, W. (1990). Perceptions of sibling relationships during middle childhood and adolescence. Child Development, 61, 1387-1398. DOI: 10.2307/1130750.

Cohen, J. (1988). Statistical power analysis for the behavioral sciences. Lawrence Erlbaum: Hillsdale, NJ.

Cole, P. M., Barrett, K. C., \& Zahn-Waxler, C. (1992). Emotion displays in 2-year-olds during mishaps. Child Development, 63, 314-324. DOI: 10.2307/1131481.

Cox, M. J., \& Paley, B. (2003). Understanding families as systems. Current Directions in Psychological Science, 12, 193-196. DOI: 10.1111/1467-8721.01259. 
Dunn, J. (1985). Sisters and brothers. Harvard University Press: Cambridge, MA.

Dunn, J., \& Munn, P. (1986). Siblings and the development of prosocial behavior. International Journal of Behavioral Development, 9, 265-284.

Dunn, J., Slomkowski, C., \& Beardsall, L. (1994). Sibling relationships from the preschool period through middle childhood and early adolescence. Developmental Psychology, 30, 315-324. DOI: 10.1037/0012-1649.30.3.315.

Faber, A., \& Mazlish, E. (1998). Siblings without rivalry. New York, NY: HarperCollins.

Goldenthal, P. (1997). Beyond sibling rivalry. Henry Holt and Company: New York, NY.

Hetherington, E. M., \& Clingempeel, W. G. (1992). Coping with marital transitions: A family systems perspective. Monographs of the Society for Research in Child Development, 57(2-3, Serial No. 227), 1-242. DOI: $10.2307 / 1166050$.

Kennedy, D. E., \& Kramer, L. (2008). Improving emotion regulation and sibling relationship quality: The More Fun With Sisters and Brothers Program. Family Relations, 57, 567-578. DOI: $10.1111 /$ j.1741-3729.2008.00523.x.

Kopp, C. B. (1989). Regulation of distress and negative emotions: A developmental view. Developmental Psychology, 25, 343-354. DOI: 10.1037/0012-1649.25.3.343.

Kreppner, K. (1988). Changes in parent-child relationships with the birth of a second child. Marriage and Family Review, 12, 157-181. DOI: 10.1300/J002v12n03.

Legg, C., Sherick, I., \& Wadland, W. (1974). Reaction of preschool children to the birth of a sibling. Child Psychiatry and Human Development, 5, 3-39. DOI: 10.1007/BF01441311.

McElwain, N. L., \& Volling. B. L. (2005). Preschool children's interactions with friends and older siblings: Relationship specificity and joint contributions to problem behavior. Journal of Family Psychology, 19, 486-496. DOI: 10.1037/0893-3200.19.4.486.

McHale, S. M., Updegraff, K. A., Jackson-Newsom, J., \& Crouter, A. C. (2000). When does parents' differential treatment have negative implications for siblings? Social Development, 9, 149-172. DOI: 10.1111/1467-9507.00117.

Miller, A. L., Volling, B. L., \& McElwain, N. L. (2000). Sibling jealousy in a triadic context with mothers and fathers. Social Development, 9(4), 433-457. DOI: 10.1111/ 1467-9507.00137.

Neubauer, P. B. (1983). The importance of the sibling experience. The Psychoanalytic Study of the Child, 38, 325-336.

Perozynski, L., \& Kramer, L. (1999). Parental beliefs about managing sibling conflict. Developmental Psychology, 35, 489-499. DOI: 10.1037/0012-1649.35.2.489.

Samalin, N., \& Whitney, C. (1997). Loving each one best: A caring and practical approach to raising siblings. New York, NY: Bantom Books.

Schaefer, E., \& Edgerton, M. (1981). The sibling inventory of behavior. University of North Carolina: Chapel Hill, NC.

Sroufe, L. A. (1996). Emotional development: The organization of emotional life in the early years. New York, NY: Cambridge University Press.

Stoneman, Z., Brody, G. H., \& MacKinnon, C. (1984). Naturalistic observations of children's activities and roles while playing with their siblings and friends. Child Development, 55, 617-627. DOI: 10.2307/1129973.

Vandell, D. L., Minnett, A. M., \& Santrock, J. W. (1987). Age differences in sibling relationships during middle childhood. Journal of Applied Developmental Psychology, 8, 247-257. DOI: 10.1016/0193-3973(87)90002-5.

Volling, B. L., Kennedy, D. E., \& Jackey, L. M. H. (2010). The development of sibling jealousy. In M. Legerstee, \& S. Hart (Eds.), Handbook of jealousy: Theory, research, and multidisciplinary approaches. Malden, MA: Blackwell Publishers.

Volling, B. L., McElwain, N. L., \& Miller, A. L. (2002). Emotion regulation in context: The jealousy complex between young siblings and its relations with child and family characteristics. Child Development, 73, 581-600. DOI: 10.1111/1467-8624.00425.

White, G. L., \& Mullen, P. E. (1989). Jealousy: Theory, research, and clinical strategies. New York: Guilford Press. 